\title{
SINTESIS DAN KARAKTERISASI NANOSTRUKTUR TEMBAGA OKSIDA DENGAN METODE HIDROTERMAL
}

\author{
CITRA DELIANA DEWI SUNDARI ${ }^{*}{ }^{*}$, RENI FITRIANI RAHAYU ${ }^{1}$, NENENG WindAYANI ${ }^{1}$ \\ ${ }^{1}$ Program Studi Pendidikan Kimia, Fakultas Tarbiyah dan Keguruan, UIN Sunan Gunung Djati Bandung, \\ Jl. A.H. Nasution No. 105 Cipadung, Bandung 40614 \\ *alamat email korespondensi: citra@uinsgd.ac.id
}

\begin{tabular}{|c|c|}
\hline Riwayat Naskah & Abstrak/Abstract \\
\hline $\begin{array}{l}\text { Riwayat Naskah : } \\
\text { Diterima pada } 9 \text { Mei } \\
2018 \\
\text { Diterima setelah } \\
\text { direvisi pada } 8 \text { Juni } \\
2018 \\
\text { Diterbitkan pada } 28 \\
\text { Juni } 2018\end{array}$ & $\begin{array}{l}\text { Karakteristik material tembaga oksida (CuO) bergantung pada struktur dan morfologinya. } \\
\text { Prosedur sintesis tembaga oksida memberikan pengaruh yang signifikan terhadap struktur dan } \\
\text { morfologi material yang dihasilkan. Pada penelitian ini, nanostruktur tembaga oksida } \\
\text { disintesis melalui proses hidrotermal dengan prosedur yang relatif sederhana. Karakterisasi } \\
\text { terhadap sampel } \mathrm{CuO} \text { yang dihasilkan menunjukkan morfologi partikel yang tidak beraturan } \\
\text { dan berongga dengan ukuran partikel berkisar antara } 300-800 \mathrm{~nm} \text { dan ukuran rongga berkisar } \\
\text { antara } 100-300 \mathrm{~nm} \text {. Struktur CuO dikonfirmasi dengan adanya puncak difraksi karakteristik } \\
\mathrm{CuO} \text { pada sudut difraksi }(2 \theta) 35,29^{\circ} \text { dan } 38,50^{\circ} \text {. Nanostruktur CuO yang dihasilkan } \\
\text { memperlihatkan serapan maksimum pada panjang gelombang } 416-422 \mathrm{~nm} \text {. }\end{array}$ \\
\hline
\end{tabular}

Kata Kunci: tembaga

Copper oxide $(\mathrm{CuO})$ material characteristics depend on the structure and morphology. The oksida; nanostruktur $\mathrm{CuO}$; metode hidrotermal. procedure for the synthesis of copper oxide has a significant influence on the structure and morphology of the material produced. In this study, copper oxide nanostructure have been synthesized via hydrothermal method with a relatively simple procedure. Characterization of the $\mathrm{CuO}$ sample produced showed irregular shape with particle sizes ranging from 300-800

Keywords: copper

oxide; $\mathrm{CuO}$

nanostructures;

hydrothermal $\mathrm{nm}$ and cavity sizes ranging from 100 to $300 \mathrm{~nm}$. CuO structure was confirmed by the presence of $\mathrm{CuO}$ diffraction characteristics at diffraction angles (20) $35.29^{\circ}$ and $38.50^{\circ}$. The resulting $\mathrm{CuO}$ nanostructure absorb visible light at maximum wavelengths of $416-422 \mathrm{~nm}$.

method.

\section{PENDAHULUAN}

Tembaga (II) oksida (CuO) merupakan salah satu senyawa oksida logam transisi yang memiliki karakteristik menarik sebagai semikonduktor tipe-p. Oksida logam transisi ini memiliki celah pita energi (band gap) yang sempit, yaitu 1,2 eV pada fasa ruah (bulk) [1]. Karena sifatnya ini, tembaga (II) oksida dapat diaplikasikan sebagai sel surya, fotodetektor, fotokatalis, dan field emission displays (FEDs). Dalam aplikasi fotovoltaik sendiri, $\mathrm{CuO}$ banyak menarik perhatian karena harganya yang relatif murah, absorbansi cahaya yang tinggi, emisi termal yang rendah, tidak beracun, serta proses pembuatan yang relatif sederhana [2,3]. Selain itu, material ini memiliki kestabilan dan sifat listrik yang baik [4,5]. Material ini juga merupakan bahan dasar bagi beberapa superkonduktor suhu tinggi dan material GMR (giant magneto resistance) [6-12]. Untuk aplikasi-aplikasi tersebut, ukuran dan bentuk/morfologi material memainkan peranan penting, karena ukuran dan morfologi yang berbeda akan menyebabkan perbedaan karakteristik material tersebut [13].

Prosedur sintesis tembaga (II) oksida memberikan pengaruh yang signifikan terhadap ukuran dan morfologi material yang dihasilkan [13]. Penelitian-penelitian sebelumnya telah berhasil mensintesis nanostruktur $\mathrm{CuO}$ melalui berbagai metode, diantaranya rute wet-chemistry [14], preparasi sonokimia [15], reaksi fasa padatan [16], proses sol gel [17], dan lain-lain.

Pada penelitian ini, nanostruktur $\mathrm{CuO}$ disintesis menggunakan metode hidrotermal. Metode ini dipilih karena memiliki beberapa kelebihan diantaranya kondisi sintesis yang relatif ringan (suhu reaksi kurang dari $300^{\circ} \mathrm{C}$ ), prosedur sintesis yang relatif sederhana (sintesis satu tahap), ramah lingkungan, dan relatif murah [18]. Karakterisasi struktur dan morfologi oksida tembaga yang dihasilkan diukur dengan $X$-ray diffraction (XRD) spectrometer dan scanning electron microscopy (SEM). Karakteristik serapan cahaya dari $\mathrm{CuO}$ yang disintesis diukur dengan $\mathrm{UV}-\mathrm{V}$ is spectrometer.

\section{EKSPERIMEN}

Pada penelitian ini, nanostruktur tembaga oksida disintesis dengan menggunakan metode sintesis hidrotermal pada larutan prekursor $\mathrm{Cu}$ (II) yang dibasakan. 


\section{Material}

Bahan-bahan yang digunakan pada penelitian ini antara lain $\mathrm{CuSO}_{4} .5 \mathrm{H}_{2} \mathrm{O}$ (p.a. Merck), demineralized water (aqua $\mathrm{dm}$ ) dan $\mathrm{NaOH}$ (p.a. Merck).

\section{Instrumentasi}

Instrumen yang digunakan untuk sintesis hidrotermal pada penelitian ini antara lain autoclave, pemanas/oven Memmert, X-ray Diffraction (XRD) PANalytical X'Pert PRO PW3040/x0, Scanning Electron Microscope (SEM) JEOL JSM-6360LA, UV-Vis spectrometer Thermo Scientific Tipe Genesys 10s.

\section{Prosedur}

Larutan prekursor tembaga oksida dibuat dengan melarutkan $\mathrm{CuSO}_{4} .5 \mathrm{H}_{2} \mathrm{O}$ dalam aqua $\mathrm{dm}$ hingga konsentrasinya $0,1 \mathrm{M}$. Larutan prekursor dibuat menjadi basa dengan ditambahkan larutan $\mathrm{NaOH}$ sambil diaduk terus-menerus hingga tercapai $\mathrm{pH}$ 12. Larutan yang dihasilkan dimasukkan ke dalam autoclave, lalu dipanaskan dalam oven pada suhu $150^{\circ} \mathrm{C}$ selama 5 jam. Padatan yang dihasilkan dipisahkan dari fasa larutannya dengan sentrifugasi. Padatan dicuci dan dikeringkan di dalam oven selama semalam pada suhu $200^{\circ} \mathrm{C}$. Serbuk tembaga oksida yang dihasilkan kemudian dikarakterisasi XRD, SEM, dan UV-Vis.

\section{HASIL DAN PEMBAHASAN}

Karakteristik struktur tembaga (II) oksida $(\mathrm{CuO})$ yang dihasilkan dapat dilihat pada pola difraksi X-ray yang disajikan pada Gambar 1. Pada pola difraksi $\mathrm{CuO}$ yang dihasilkan terlihat adanya puncak-puncak utama yang merupakan puncak karakteristik dari nanostruktur $\mathrm{CuO}$ yaitu pada sudut $2 \theta$ sebesar $35,29^{\circ}$ dan $38,50^{\circ}$. Hasil yang didapat ini juga dikonfirmasi oleh $\mathrm{Z}$. Hong et al. [19].

Selain dua puncak utama tersebut, puncakpuncak karakteristik nanostruktur $\mathrm{CuO}$ yang terbentuk juga muncul pada sudut $2 \theta$ sebesar $48,63^{\circ} ; 58,25^{\circ} ; 61,40^{\circ} ; 65,94^{\circ} ; 67,98^{\circ}$ dan $74,89^{\circ}$. Puncak-puncak fasa $\mathrm{CuO}$ yang muncul sesuai dengan kartu standar JCPDS No. 41-0254. Puncak karakteristik nanostruktur $\mathrm{CuO}$ memiliki intensitas tinggi, yang menunjukkan bahwa nanostruktur $\mathrm{CuO}$ yang terbentuk memiliki kristalinitas cukup baik.

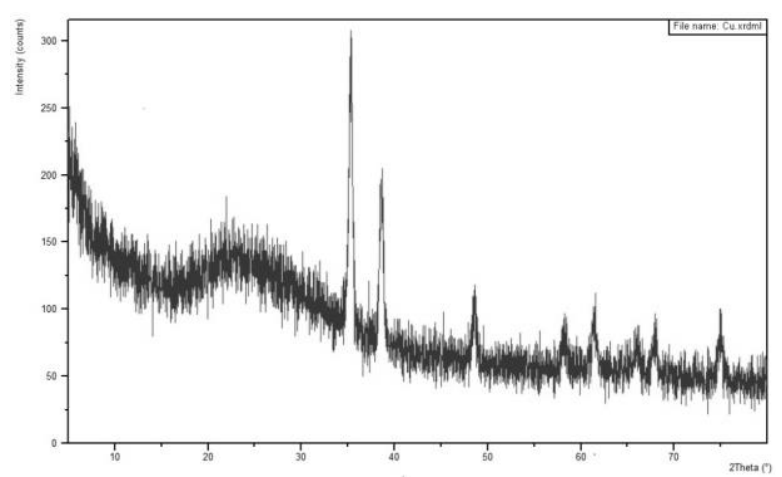

Gambar 1. Pola difraksi X-ray sampel CuO

Morfologi sampel padatan $\mathrm{CuO}$ hasil sintesis dilihat dengan menggunakan SEM perbesaran 50.000 kali yang dapat dilihat pada Gambar 2. Pada Gambar 2 terlihat bentuk partikel $\mathrm{CuO}$ yang kurang beraturan, namun ukuran partikel $\mathrm{CuO}$ yang terbentuk berada pada orde nanometer dengan ukuran partikel sekitar 300-800 nm. Mikrograf sampel juga menunjukkan adanya rongga antarpartikel dengan lebar berkisar antara 100 sampai $300 \mathrm{~nm}$. Nanostruktur $\mathrm{CuO}$ yang dihasilkan memiliki ukuran yang relatif besar (mendekati $1 \mu \mathrm{m}$ ) yang dapat disebabkan oleh pengaturan $\mathrm{pH}$ larutan prekursor yang terlalu tinggi sehingga memicu terbentuknya padatan hidroksida yang cepat pada fasa larutan.

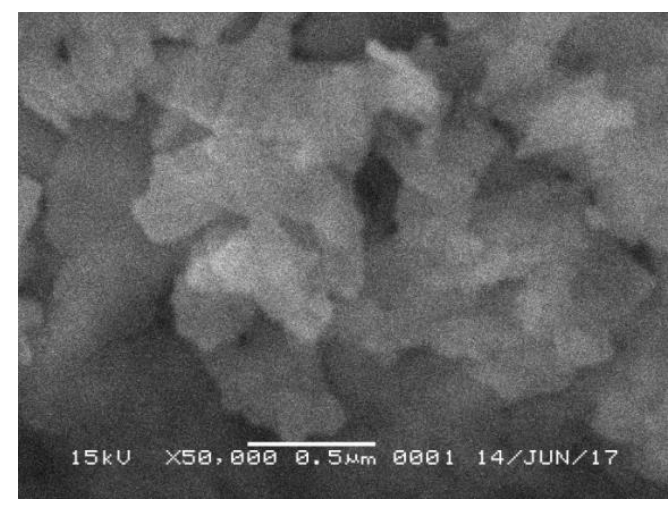

Gambar 2. Mikrograf SEM sampel CuO hasil sintesis

Sampel $\mathrm{CuO}$ yang dihasilkan dikarakterisasi sifat optis/serapan cahayanya melalui pengukuran spektrun UV-Vis yang hasilnya dapat dilihat pada Gambar 3. Pengukuran serapan cahaya pada sampel $\mathrm{CuO}$ menunjukkan adanya serapan maksimum cahaya tampak pada panjang gelombang, $\lambda_{\text {maks }}, 416 \mathrm{~nm}$ sampai $422 \mathrm{~nm}$. Nilai serapan pada $\lambda_{\text {maks }}$ ini dapat digunakan untuk memperkirakan nilai celah pita energi (band gap) dari sampel nanostruktur $\mathrm{CuO}$ hasil sintesis.

Dari nilai $\lambda_{\text {maks }}$ yang terukur pada serapan UV-Vis, didapatkan nilai perkiraan celah pita energi (band gap) sebesar 2,94 eV sampai 2,98 $\mathrm{eV}$. Terdapat perbedaan nilai celah pita energi 
(band gap) sampel nanostruktur $\mathrm{CuO}$ hasil sintesis dengan nilai band gap $\mathrm{CuO}$ fasa ruah $(1,2 \mathrm{eV}$ [1]). $\mathrm{Hal}$ ini dapat disebabkan oleh ukuran partikel $\mathrm{CuO}$ hasil sintesis yang berada pada orde nanometer. Berdasarkan hasil penelitian Rehman S. et al., semakin kecil ukuran partikel oksida $\mathrm{CuO}$ maka semakin besar nilai celah pita energinya (band gap-nya) [20].

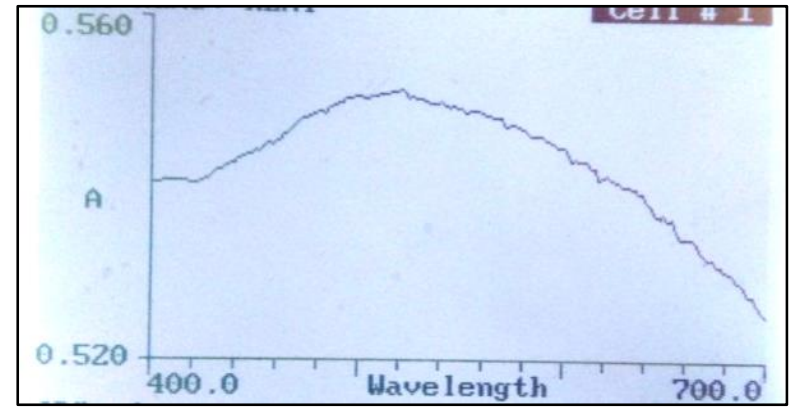

Gambar 3. Spektrum serapan UV-Vis sampel $\mathrm{CuO}$

\section{SIMPULAN}

Nanostruktur tembaga oksida $(\mathrm{CuO})$ telah berhasil disintesis dengan menggunakan metode hidrotermal dari prekursor larutan tembaga sulfat. Hasil karakterisasi nanostruktur tembaga oksida hasil sintesis menunjukkan adanya puncak difraksi karakteristik $\mathrm{CuO}$ pada sudut difraksi (20) 35,29 dan $38,50^{\circ}$, morfologi partikel yang tidak beraturan dan berongga dengan ukuran partikel berkisar antara 300-800 $\mathrm{nm}$ dan ukuran rongga berskisar 100-300 $\mathrm{nm}$, dan serapan maksimum dari sampel $\mathrm{CuO}$ yang terukur pada panjang gelombang 416-422 $\mathrm{nm}$.

\section{REFERENSI}

[1] D. P. Singh, N. Ali, "Synthesis of $\mathrm{TiO}_{2}$ and $\mathrm{CuO}$ nanotubes and nanowires", Science of Advanced Materials, vol. 2, pp. 295-335, 2010.

[2] A. H. Jayatissa, K. Guo, A. C. Jayasuriya, "Fabrication of cuprous and cupric oxide thin films by heat treatment", Applied Surface Science, vol. 255, pp. 9474-9, 2009.

[3] A. Ogwu, T. Darma, E. Bouquerel, "Electrical resistivity of copper oxide thin films prepared by reactive magnetron sputtering", Journal of Achievements of Materials and Manufacturing Engineering, vol. 24, pp. 172-7, 2007.

[4] M. Vaseem, A. Umar, S. H. Kim, Y-B. Hahn, "Low-temperature synthesis of flower-shaped $\mathrm{CuO}$ nanostructures by solution process: formation mechanism and structural properties", The Journal of Physical
Chemistry C, vol. 112, pp. 5729-35, 2008.

[5] D. Chauhan, V. Satsangi, S. Dass, R. Shrivastav, "Preparation and characterization of nanostructured $\mathrm{CuO}$ thin films for photoelectrochemical splitting of water", Bulletin of Materials Science, vol. 29, pp. 709-16, 2006.

[6] S. Anandan, S. Yang, "Emergent methods to synthesize and characterize semiconductor $\mathrm{CuO}$ nanoparticles with various morphologies-an overview", Journal of Experimental Nanoscience, vol. 7, no. 2, pp. 23-56, 2007.

[7] Y. Li, X. Y. Yang, Y. Feng, Z. Y. Yuan, B. L. $\mathrm{Su}$, "One-dimensional metal oxide nanotubes, nanowires, nanoribbons, and nanorods: synthesis, characterizations, properties and applications", Critical Reviews in Solid State and Materials Sciences, vol. 37, pp. 1-74, 2012.

[8] G. Filipic, U. Cvelbar, "Copper oxide nanowires: a review of growth", Nanotechnology, vol. 23, pp. 194001, 2012.

[9] Y. Liu, Y. Chu, Y. Zhuo, M. Li, L. Li, L. Dong, "Anion-controlled construction of $\mathrm{CuO}$ honeycombs and flowerlike assemblies on copper foils", Crystal Growth \& Design, vol. 7, pp. 467-70, 2007.

[10] M. Vaseem, A. Umar, S. H. Kim, Y-B. Hahn, "Low-temperature synthesis of flower-shaped $\mathrm{CuO}$ nanostructures by solution process: formation mechanism and structural properties", The Journal of Physical Chemistry C, vol. 112, pp. 5729-35, 2008.

[11] X. Zheng, C. Xu, Y. Tomokiyo, E. Tanaka, H. Yamada, Y. Soejima, "Observation of charge stripes in cupric oxide", Physical Review Letters, vol. 85, pp. 5170-3, 2000.

[12] aH. MacDonald, "Copper oxides get charged up", Nature, vol. 414, pp. 409-10, 2001.

[13] P. Mallick, S. Sahu, "Structure, Microstructure and Optical Absorption Analysis of $\mathrm{CuO}$ Nanoparticles Synthesized by Sol-Gel Route", Nanoscience and Nanotechnology, vol. 2, no. 3, pp. 71-74, 2012.

[14] X. P. Gao, J. L. Bao and G. L. Pan, "Preparation and Electro-chemical Performance of Polycrystalline and Single Crystal-line $\mathrm{CuO}$ Nanorods as Anode Materials for Li Ion Battery", The Journal of 
Physical Chemistry B, vol. 108, pp. 5547, 2004.

[15] R. Vijaya Kumar, R. Elgamiel, Y. Diamant, and A. Gedanken, "Sonochemical Preparation and Characterization of Nano-crystalline Copper Oxide Embedded in Poly(vinyl alcohol) and Its Effect on Crystal Growth of Copper Oxide", Langmuir, vol. 17, pp. 1406, 2001.

[16] W. Wang, Y. Zhan and G. Wang, "One-step, solid-state reaction to the synthesis of copper oxide nanorods in the presence of a suitable surfactant", Chemical Communications, pp. 727, 2001.

[17] M. Bibi, Q. A. Javed, H. Abbas, S. Baqi, "Outcome of temperature variation on sol-gel prepared $\mathrm{CuO}$ nanostructure properties (optical and dielectric)", Materials Chemistry and Physics, vol. 192, pp. 67-71, 2017. ferroelectric nanocrystal/polymer composites", Physical Properties and Applications of Polymer Nanocomposites, pp. 108-158, 2010.

[19] Zhong-shan Hong, Yong Cao, Jing-fa Deng, "A convenient alcohothermal approach for low temperature synthesis of $\mathrm{CuO}$ nanoparticles", Materials Letters 52Ž2002.3438.

[20] S. Rehman, A. Mumtaz, S. K. Hasanain, "Size effects on the magnetic and optical properties of $\mathrm{CuO}$ nanoparticles," Journal of Nanoparticle Research, vol. 13, no. 6, pp. 2497-507, 2011.

[18] A. D. Li, W. C. Liu, "Optical properties of 